\title{
Molecular profile of major growth factors in lumbar intervertebral disc herniation: Correlation with patient clinical and epidemiological characteristics
}

\author{
ALEXANDROS TSAROUHAS ${ }^{1}$, GIANNOULA SOUFLA ${ }^{1,2}$, KONSTANTINOS TSAROUHAS $^{3}$, PAVLOS KATONIS $^{4}$, \\ DRITAN PASKU ${ }^{1,4}$, ANTONIS VAKIS ${ }^{5}$, ARISTIDES M. TSATSAKIS ${ }^{6}$ and DEMETRIOS A. SPANDIDOS ${ }^{1}$ \\ ${ }^{1}$ Laboratory of Virology, Medical School, University of Crete, Heraklion 71003; ${ }^{2}$ Department of Coagulation and Haemostasis, \\ Onassis Cardiac Surgery Center, Athens 17674; ${ }^{3}$ Cardiological Department, University General Hospital of Larissa, \\ Larissa 41110; Departments of ${ }^{4}$ Orthopedics and Traumatology, and ${ }^{5}$ Neurosurgery, University Hospital of Heraklion, \\ Heraklion 71110; ${ }^{6}$ Department of Forensic Sciences and Toxicology, Faculty of Medicine, \\ University of Crete, Heraklion 71003, Greece
}

Received October 7, 2016; Accepted January 27, 2017

DOI: $10.3892 / \mathrm{mmr} .2017 .6221$

\begin{abstract}
The involvement of growth factors (GFs) in the pathogenesis of lumbar intervertebral disc (ID) herniation and the spontaneous resorption of herniated ID fragments remains only partially elucidated. A simultaneous assessment of the transcript levels of numerous GFs and their association with clinical and epidemiological profiles of human ID herniation would provide valuable insight into the biology and clinical course of the disease. In the present study, we examined simultaneously the transcript levels of vascular endothelial growth factor (VEGF), transforming growth factor $\beta 1$ (TGF- $\beta 1$ ), basic fibroblast growth factor 2 (bFGF2), platelet derived growth factor (PDGF) isoforms and receptors, epidermal growth factor (EGF) and insulin growth factor-1 (IGF-1) in herniated and control ID specimens and investigated their correlation with the clinicopathological profiles of patients suffering from symptomatic lumbar ID herniation. GF mRNA expression levels were determined by RT-qPCR in 63 surgical specimens from lumbar herniated discs and 10 control ID specimens. Multiple positive correlations were observed between the transcript levels of the GFs examined in the ID herniation group. VEGF mRNA expression was significantly increased in the protruding compared with the extruded discs. Intense and acute pain significantly upregulated the PDGF transcript levels. Significant negative correlations were observed between the patient body mass index and the transcript levels of VEGF and PDGF receptors. Our findings support the hypothesis of the involvement of GFs in the natural history of ID herniation. GFs
\end{abstract}

Correspondence to: Professor D.A. Spandidos, Laboratory of Virology, Medical School, University of Crete, Voutes, Heraklion 71003, Crete, Greece

E-mail: spandidos@spandidos.gr

Key words: growth factors, intervertebral disk, herniation, reverse transcription-quantitative PCR synergistically act in herniated IDs. Increased VEGF expression possibly induces the neovascularization process in the earliest stages of ID herniation. PDGF-C and -D play a role in the acute phase of radiculopathy in a metabolic response for tissue healing. A molecular effect, in addition to the biomechanical effect of obesity in the pathogenesis of ID herniation is also implied.

\section{Introduction}

Intervertebral disc (ID) herniation is a common, yet poorly understood disorder. Behavioral, hereditary and environmental factors cumulatively affect the nutrition and homeostasis of the disc, ultimately resulting in its structural breakdown and in the occurrence of herniation. The incidence of symptomatic lumbar ID herniation in the United States is estimated at $1-2 \%$, for which approximately 200,000 discectomies are performed annually (1). The direct costs for conservative or surgical treatment and he indirect costs deriving from the loss of productivity are enormous (2).

However, ID herniation is considered to present a favorable natural history. Sequential magnetic resonance imaging (MRI) studies have documented that the majority of disc herniations diminish in size (3). Saal et al reported that almost $80 \%$ of disc herniations treated non-operatively decreased by $>50 \%$ in follow-up examinations (4). In addition, a positive correlation has been found between the regression of disc herniation and the remission of symptoms $(3,4)$. Various molecules, such as pro-inflammatory cytokines, growth factors (GFs) and matrix metalloproteinases (MMPs) have been implicated in the mechanisms that regulate ID degradation and herniation, as well as the spontaneous resorption of herniated disc fragments (5).

GFs are polypeptides involved in the modulation of cell growth and differentiation that exert their biologic effects through endocrine, paracrine and autocrine pathways (6). Over 18 different GFs have been identified, including vascular endothelial growth factor (VEGF), transforming growth factor $\beta 1$ (TGF- $\beta 1$ ), basic fibroblast growth factor (bFGF)-2, platelet derived growth 
factor (PDGF), epidermal growth factor (EGF) and insulin growth factor-1 (IGF-1). The PDGF family in particular is formed by the PDGF-A, -B, -C and -D isoforms that are encoded by four genes located at different chromosomes and may form homodimers, as well as heterodimers. These molecules signal through two cell-surface receptors, PDGF-R $\alpha$ and $\beta$ (7).

To date, the expression of various GFs in the degenerate and herniated ID has been investigated in numerous studies. The increased protein expression of IGF-1, FGF-2, VEGF, PDGF and TGF- $\beta$ has been found by means of immunohistochemistry (8-11). The transcript levels of TGF- $\beta$ and VEGF have also been examined in human ID herniation specimens (12). Consequently, preliminary studies have examined the effect of administering different GFs on ID physiology and degeneration in vitro and in vivo $(13,14)$. However, a simultaneous assessment of the molecular profile of numerous GFs in human herniated IDs has not been performed to date, at least to the best of our knowledge. In addition, clinical and epidemiological determinants, such as the extent of disc herniation, the duration and intensity of symptoms, age and employment may considerably affect the pathophysiology of ID degeneration and the potential for regression of herniated ID fragments. The association between the clinical, epidemiological and molecular profile of ID herniation would potentially provide valuable insight into the biology and clinical course of the disorder. Therefore, the purpose of the present study was to simultaneously examine the molecular profiles of numerous GFs by means of reverse transcriprtion-quantitative polymerase chain reaction (RT-qPCR), and to investigate potential correlations with the clinical and epidemiological characteristics of patients suffering from lumbar ID herniation.

\section{Materials and methods}

Tissue samples. ID tissue samples were collected from a total of 63 patients who underwent posterior open discectomy for lumbar ID herniation in our department during a recruitment period of one year (2008). The patients reported symptoms of radiculopathy prior to surgery. Patients suffering from spinal stenosis, spondylolisthesis, scoliosis or systemic inflammatory disorders were excluded from the study. After excision, an experienced pathologist, in addition to the clinicians present, examined the tissue samples and identified the pulposus sections in order to limit the percentage of end-plates or annulus. Samples were then immediately refrigerated at $-80^{\circ} \mathrm{C}$ until RNA extraction. Ten cadaveric ID tissue samples were also obtained within $12 \mathrm{~h}$ of the patient succumbing to the disease, referring to various diseases other than ID herniation. The samples were used as controls of normal growth factor mRNA expression. Donors were aged between 20 and 46 years and were known to have a negative history of lower back pain, spinal trauma or systemic inflammatory disease. All the patients or relatives signed an informed consent form approved by the University Ethics Committee to participate in the present study. The study design was in accordance with the Declaration of Helsinki Guidelines.

Prior to surgery, the patients routinely underwent an MRI examination for the classification of ID herniation. The recommendations of the combined task force from the North American Spine Society, the American Society of Spine Radiology and the American Society of Neuroradiology based on the imaging
Table I. Patient clinical characteristics.

\begin{tabular}{|c|c|}
\hline Characteristic & No. of patients \\
\hline \multicolumn{2}{|l|}{ ID herniation group } \\
\hline \multicolumn{2}{|l|}{ Age (years) } \\
\hline Mean (range) & $47.3(27-68)$ \\
\hline $20-39$ & 27 \\
\hline $40-59$ & 23 \\
\hline$>60$ & 12 \\
\hline \multicolumn{2}{|l|}{ Gender } \\
\hline Male/female & $33 / 30$ \\
\hline \multicolumn{2}{|l|}{ Body mass index (BMI) } \\
\hline Mean (range) & $27.2(21.07-33.05)$ \\
\hline \multicolumn{2}{|l|}{ Level of ID herniation } \\
\hline L3-L4 & 11 \\
\hline L4-L5 & 24 \\
\hline L5-S1 & 28 \\
\hline \multicolumn{2}{|l|}{ Type of herniation } \\
\hline Protrusion & 23 \\
\hline Extrusion & 33 \\
\hline Sequestration & 7 \\
\hline \multicolumn{2}{|l|}{ Duration of symptoms } \\
\hline$<3$ months & 15 \\
\hline 3-12 months & 20 \\
\hline$>12$ months & 28 \\
\hline \multicolumn{2}{|l|}{ Pain intensity (VAS) } \\
\hline $0-5$ & 18 \\
\hline $5-7$ & 14 \\
\hline $8-10$ & 31 \\
\hline \multicolumn{2}{|l|}{ Employment } \\
\hline Heavy/light & $36 / 27$ \\
\hline \multicolumn{2}{|l|}{ Smoking Habits } \\
\hline Smokers/non-smokers & $26 / 37$ \\
\hline$<10$ cig per day & 6 \\
\hline 10- 20 cig per day & 8 \\
\hline$>20$ cig per day & 12 \\
\hline \multicolumn{2}{|l|}{ Control group } \\
\hline \multicolumn{2}{|l|}{ Age (years) } \\
\hline Mean (range) & $36.8(20-46)$ \\
\hline \multicolumn{2}{|l|}{ Gender } \\
\hline Male/female & $6 / 4$ \\
\hline \multicolumn{2}{|l|}{ Body mass index (BMI) } \\
\hline Mean (range) & $27.0(21.9-33.0)$ \\
\hline \multicolumn{2}{|l|}{ Employment } \\
\hline Heavy/light & $7 / 3$ \\
\hline \multicolumn{2}{|l|}{ Smoking Habits } \\
\hline Smokers/non-smokers & $4 / 6$ \\
\hline
\end{tabular}

characterization of Milette (15) were used to determine the type of ID herniation. Pre-operative pain intensity was measured subjectively using the visual analogue scale score (VAS). Patient employment was defined as heavy if it included manual labour with repetitive loading of the spine. A summary of patient and control group baseline data is presented in Table I. There were no significant differences in terms of age, gender, body mass 
Table II. Sequences of primers used for RT-qPCR.

\begin{tabular}{|c|c|c|c|}
\hline Gene & Primer pair sequence $\left(5^{\prime} \rightarrow 3^{\prime}\right)$ & $\begin{array}{c}\text { Annealing } \\
\text { temperature }\left({ }^{\circ} \mathrm{C}\right)\end{array}$ & $\begin{array}{l}\text { Product size } \\
\quad(b p)\end{array}$ \\
\hline IGF-1 & $\begin{array}{l}\text { CCTCCTCGCATCTCTTCTACCTGC } \\
\text { TGCTGGAGCCATACCCTGTG }\end{array}$ & 60 & 166 \\
\hline FGF-2 & $\begin{array}{l}\text { CTGGCTATGAAGGAAGATGGA } \\
\text { TGCCCAGTTCGTTTCAGTG }\end{array}$ & 55 & 149 \\
\hline TGF-B & $\begin{array}{l}\text { AAGGACCTCGGCTGGAAGTGC } \\
\text { CCGGGTTATGCTGGTTGTA }\end{array}$ & 62 & 137 \\
\hline VEGF & $\begin{array}{l}\text { ATGACGAGGGCCTGGAGTGTG } \\
\text { CCTATGTGCTGGCCTTGGTGAG }\end{array}$ & 60 & 91 \\
\hline PDGF-A & $\begin{array}{l}\text { ACACGAGCAGTGTCAAGTGC } \\
\text { CCTGACGTATTCCACCTTGG }\end{array}$ & 55 & 76 \\
\hline PDGF-B & $\begin{array}{l}\text { AGATCGAGATTGTGCGGAAG } \\
\text { CAGCTGCCACTGTCTCACAC }\end{array}$ & 52 & 94 \\
\hline PDGF-C & $\begin{array}{l}\text { GCCAGGTTGTCTCCTGGTTA } \\
\text { TGCTTGGGACACATTGACAT }\end{array}$ & 52 & 86 \\
\hline PDGF-D & $\begin{array}{l}\text { CCCAGGAATTACTCGGTCAA } \\
\text { ACAGCCACAATTTCCTCCAC }\end{array}$ & 52 & 105 \\
\hline PDGF rec-A & $\begin{array}{l}\text { TGGGAGTTTCCAAGAGATGG } \\
\text { TGTTCCTTCAACCACCTTCC }\end{array}$ & 52 & 78 \\
\hline PDGF rec-B & $\begin{array}{l}\text { GTGCTCACCATCATCTCCCT } \\
\text { ACTCAATCACCTTCCATCGG }\end{array}$ & 52 & 85 \\
\hline GAPDH & $\begin{array}{l}\text { GGAAGGTGAAGGTCGGAGTCA } \\
\text { GTCATTGATGGCAACAATATCCACT }\end{array}$ & 60 & 101 \\
\hline
\end{tabular}

index (BMI), employment and smoking habits between the control and ID herniation groups (minimum $\mathrm{P}=0.24$ ).

RNA extraction and RT-qPCR. Total RNA was isolated from fresh tissue and homogenized with a power homogenizer using TRIzol reagent (Invitrogen, Carlsbad, CA, USA). RNA concentration and purity were determined on a UV spectrophotometer (Hitachi Instruments Inc., San Jose, CA, USA) by absorbance measurements (260 nm absorbance and 260/280 nm absorbance ratio). RNA integrity was examined by $1 \%$ agarose gel electrophoresis and ethidium bromide staining.

Reverse transcription reactions for the preparation of first-strand cDNA from $2 \mu \mathrm{g}$ of total RNA were performed using the AffinityScript ${ }^{\mathrm{TM}}$ Multi Temperature cDNA synthesis kit (Stratagene, La Jolla, CA, USA). Random hexamers were used as amplification primers. Quantitative PCR (qPCR) reactions were performed using the Mx3000P real-time PCR system with SYBR ${ }^{\circledR}$-Green I Master Mix (both from Stratagene). Data were collected and analyzed using the Mx3000P real-time PCR software version 2.00, Build 215 Schema 60 (Stratagene). Glyceraldehyde-3-phosphate dehydrogenase (GAPDH) was used as an internal control to normalize the mRNA expression levels of the GFs examined. The primer pair sequences used are listed in Table II. PCR products were analyzed by electrophoresis on $2 \%$ agarose gels, stained with ethidium bromide and photographed on a UV light transilluminator. GF transcription levels were calculated using the following formula: normalized sample or control $=\left(1+\mathrm{E}_{\mathrm{GF}}\right)^{-\Delta \Delta \mathrm{Cq}} \mathrm{GF} /\left(1+\mathrm{E}_{\mathrm{GAPDH}}\right)^{-\Delta \Delta \mathrm{Cq}} \mathrm{GAPDH}$. Procedures were repeated with a cDNA template, synthesized three times from the same RNA. The mRNA levels of each sample for each gene tested represent the mean value of data acquired from three independent RT-qPCR experiments. The reproducibility of the RT-qPCR results for the same samples was $99 \%$.

Statistical analysis. The one-sample Kolmogorov-Smirnov test was used to assess the normality of the distribution of the mRNA expression values for the genes studied. Accordingly, the mRNA expression levels of the GFs examined in the control and herniated groups were compared using parametric and non-parametric procedures, respectively. Differences in GF expression between herniated and control IDs and between subgroups of different clinical characteristics were examined using parametric (one-way and repeated measures ANOVA) and non-parametric (Kruskal-Wallis and Mann-Whitney) tests accordingly. Pairwise comparisons were performed to further explore the interaction. Categorical variables were compared with the use of $\chi^{2}$ test. The Spearman rank correlation test (non-parametric) was also employed to examine pair-wise correlations in growth factor mRNA expression in control and herniated discs. The significance level was set at $\mathrm{P}<0.05$. Statistical calculations were performed using SPSS software, version 15 (SPSS, Inc., Chicago, IL, USA).

\section{Results}

GF mRNA levels in normal and herniated discs. The transcript levels of the GFs examined were not significant between 
Table III. Growth factor mRNA expression.

\begin{tabular}{lcccccc}
\hline $\begin{array}{l}\text { Expressed } \\
\text { Gene }\end{array}$ & $\begin{array}{c}\text { Control discs } \\
(\mathrm{n}=10)\end{array}$ & $\begin{array}{c}\text { Herniated discs } \\
(\mathrm{n}=63)\end{array}$ & $\begin{array}{c}\text { P-value } \\
\text { a }\end{array}$ & $\begin{array}{c}\text { Control discs } \\
(\mathrm{n}=10)\end{array}$ & $\begin{array}{c}\text { Herniated discs (\%) } \\
(\mathrm{n}=63)\end{array}$ & P-value $^{\mathrm{b}}$ \\
\hline IGF & $1.2637 \pm 0.961$ & $11256.0652 \pm 1.12$ & $\mathrm{NS}$ & $5 / 10$ & $22 / 63(34.9)$ & NS \\
FGF & $0.0431 \pm 0.032$ & $46.0385 \pm 38.749$ & $\mathrm{NS}$ & $4 / 10$ & $30 / 63(47.6)$ & NS \\
TGF & $1.1329 \pm 0.616$ & $36.8798 \pm 13.531$ & NS & $9 / 10$ & $56 / 63(88.8)$ & NS \\
VEGF & $0.0003 \pm 0.001$ & $9.9859 \pm 9.7546$ & NS & $5 / 10$ & $33 / 63(52.3)$ & NS \\
PDGF-A & $0.6554 \pm 0.613$ & $24.7222 \pm 10.603$ & NS & $4 / 10$ & $31 / 63(49.2)$ & NS \\
PDGF-B & $4.5424 \pm 2.395$ & $65.3348 \pm 52.903$ & NS & $10 / 10$ & $62 / 63(98.4)$ & NS \\
PDGF-C & $1.7382 \pm 0.427$ & $121.2165 \pm 68.593$ & NS & $10 / 10$ & $63 / 63(100)$ & NS \\
PDGF-D & $3.2749 \pm 0.969$ & $153.5597 \pm 97.695$ & NS & $10 / 10$ & $63 / 63(100)$ & NS \\
PDGF rec-A & $0.1241 \pm 0.052$ & $25.8371 \pm 13.227$ & NS & $6 / 10$ & $32 / 63(50.7)$ & NS \\
PDGF rec-B & $0.0823 \pm 0.053$ & $12.5163 \pm 5.361$ & NS & $4 / 10$ & $29 / 63(46)$ & NS \\
\hline
\end{tabular}

${ }^{a}$ Mann-Whitney test, ${ }^{b} \chi^{2}$ NS, non-significant. Quantitative data are presented as the means \pm SEM, and are based on the expression status (expressed or not) in the control and herniated lumbar discs.

Table IV. Spearman correlation tables demonstrating the co-expression profile of GFs in the group of herniated lumbar discs.

\begin{tabular}{|c|c|c|c|c|c|c|c|c|c|c|c|}
\hline Factor & Method & bFGF & IGF & PDGF-A & PDGF-B & PDGF-C & PDGF-D & PDGFRA & PDGFRB & TGF-b & VEGF \\
\hline \multirow[t]{2}{*}{ bFGF } & Spearman's rho & 1.000 & & & & & & & & & \\
\hline & Sig. 2-tailed & . & & & & & & & & & \\
\hline \multirow[t]{2}{*}{ IGF } & Spearman's rho & 0.644 & 1.000 & & & & & & & & \\
\hline & Sig. 2-tailed & 0.000 & . & & & & & & & & \\
\hline \multirow[t]{2}{*}{ PDGF-A } & Spearman's rho & 0.136 & 0.181 & 1.000 & & & & & & & \\
\hline & Sig. 2-tailed & 0.294 & 0.159 & . & & & & & & & \\
\hline \multirow[t]{2}{*}{ PDGF-B } & Spearman's rho & -0.175 & -0.132 & 0.038 & 1.000 & & & & & & \\
\hline & Sig. 2-tailed & 0.171 & 0.301 & 0.767 & & & & & & & \\
\hline \multirow[t]{2}{*}{ PDGF-C } & Spearman's rho & -0.119 & -0.050 & -0.101 & 0.546 & 1.000 & & & & & \\
\hline & Sig. 2-tailed & 0.354 & 0.700 & 0.436 & 0.000 & . & & & & & \\
\hline \multirow[t]{2}{*}{ PDGF-D } & Spearman's rho & -0.151 & -0.069 & -0.091 & 0.536 & 0.728 & 1.000 & & & & \\
\hline & Sig. 2-tailed & 0.239 & 0.590 & 0.480 & 0.000 & 0.000 & . & & & & \\
\hline \multirow[t]{2}{*}{ PDGFRA } & Spearman's rho & 0.744 & 0.572 & 0.155 & -0.031 & 0.002 & -0.082 & 1.000 & & & \\
\hline & Sig. 2-tailed & 0.000 & 0.000 & 0.229 & 0.807 & 0.987 & 0.524 & & & & \\
\hline \multirow[t]{2}{*}{ PDFGRB } & Spearman's rho & 0.845 & 0.654 & 0.212 & -0.095 & -0.057 & -0.199 & 0.822 & 1.000 & & \\
\hline & Sig. 2-tailed & 0.000 & 0.000 & 0.098 & 0.457 & 0.655 & 0.118 & 0.000 & & & \\
\hline \multirow[t]{2}{*}{ TGF-b } & Spearman's rho & 0.376 & 0.325 & 0.164 & 0.060 & 0.201 & 0.168 & 0.287 & 0.365 & 1.000 & \\
\hline & Sig. 2-tailed & 0.002 & 0.009 & 0.202 & 0.638 & 0.113 & 0.188 & 0.022 & 0.003 & . & \\
\hline \multirow[t]{2}{*}{ VEGF } & Spearman's rho & 0.886 & 0.557 & 0.077 & -0.263 & 0.005 & -0.054 & 0.680 & 0.770 & 0.477 & 1.000 \\
\hline & Sig. 2-tailed & 0.000 & 0.000 & 0.552 & 0.039 & 0.967 & 0.676 & 0.000 & 0.000 & 0.000 & \\
\hline
\end{tabular}

Numbers in bold refer to statistically significant findings (correlations, 2-tailed). bFGF, basic fibroblast growth factor; IGF, insulin growth factor; PDGF, platelet derived growth factor; TGF, transforming growth factor; VEGF, vascular endothelial growth factor.

the control and ID herniation groups (minimum $\mathrm{P}=0.26$, Mann-Whitney test, Table III). With the exception of EGF that was not expressed in neither of the 2 groups, all the GFs examined were expressed in the two study groups. Specifically, the mRNA expression status (expressed or not) of the genes examined ranged from 40 to $100 \%$ in the controls and 35 to $100 \%$ in the ID herniation groups (Table III). PDGF-C and -D mRNA expression was observed in all the herniated IDs, while IGF was the least commonly expressed in the same group (34.9\%).

Pair-wise GF mRNA co-expression analysis. Pair-wise correlations between the genes examined in the ID herniation groups and the controls are presented in Tables IV and V, respectively (Spearman correlations). Compared with the 
Table V. Spearman correlation tables demonstrating the co- expression profile of GFs in the group of control lumbar discs.

\begin{tabular}{|c|c|c|c|c|c|c|c|c|c|c|c|}
\hline Factor & Method & $\mathrm{bFGF}$ & IGF & PDGF-A & PDGF-B & PDGF-C & PDGF-D & PDGFRA & PDGFRB & VEGF & TGF-b \\
\hline bFGF & $\begin{array}{l}\text { Spearman's rho } \\
\text { Sig. 2-tailed }\end{array}$ & 1.000 & & & & & & & & & \\
\hline IGF & $\begin{array}{l}\text { Spearman's rho } \\
\text { Sig. 2-tailed }\end{array}$ & $\begin{array}{r}-0.076 \\
0.886\end{array}$ & 1.000 & & & & & & & & \\
\hline PDGF-A & $\begin{array}{l}\text { Spearman's rho } \\
\text { Sig. 2-tailed }\end{array}$ & $\begin{array}{r}-0.271 \\
0.604\end{array}$ & $\begin{array}{l}0.981 \\
\mathbf{0 . 0 0 1}\end{array}$ & $\begin{array}{l}1.000 \\
.\end{array}$ & & & & & & & \\
\hline PDGF-B & $\begin{array}{l}\text { Spearman's rho } \\
\text { Sig. 2-tailed }\end{array}$ & $\begin{array}{r}-0.475 \\
0.341\end{array}$ & $\begin{array}{l}0.388 \\
0.447\end{array}$ & $\begin{array}{l}0.469 \\
0.348\end{array}$ & 1.000 & & & & & & \\
\hline PDGF-C & $\begin{array}{l}\text { Spearman's rho } \\
\text { Sig. 2-tailed }\end{array}$ & $\begin{array}{r}-0.636 \\
0.175\end{array}$ & $\begin{array}{l}0.644 \\
0.168\end{array}$ & $\begin{array}{l}0.749 \\
0.087\end{array}$ & $\begin{array}{l}0.632 \\
0.178\end{array}$ & $\begin{array}{l}1.000 \\
.\end{array}$ & & & & & \\
\hline PDGF-D & $\begin{array}{l}\text { Spearman's rho } \\
\text { Sig. 2-tailed }\end{array}$ & $\begin{array}{l}-0.86 \\
\mathbf{0 . 0 2 7}\end{array}$ & $\begin{array}{l}0.007 \\
0.989\end{array}$ & $\begin{array}{l}0.178 \\
0.735\end{array}$ & $\begin{array}{l}0.631 \\
0.179\end{array}$ & $\begin{array}{l}0.745 \\
0.089\end{array}$ & 1.000 & & & & \\
\hline PDGFRA & $\begin{array}{l}\text { Spearman's rho } \\
\text { Sig. 2-tailed }\end{array}$ & $\begin{array}{l}0.378 \\
0.460\end{array}$ & $\begin{array}{r}-0.422 \\
0.405\end{array}$ & $\begin{array}{r}-0.482 \\
0.333\end{array}$ & $\begin{array}{r}-0.677 \\
0.140\end{array}$ & $\begin{array}{r}-0.394 \\
0.440\end{array}$ & $\begin{array}{r}-0.310 \\
0.550\end{array}$ & $\begin{array}{l}1.000 \\
.\end{array}$ & & & \\
\hline PDFGRB & $\begin{array}{l}\text { Spearman's rho } \\
\text { Sig. 2-tailed }\end{array}$ & $\begin{array}{l}0.338 \\
0.512\end{array}$ & $\begin{array}{r}-0.252 \\
0.630\end{array}$ & $\begin{array}{r}-0.308 \\
0.553\end{array}$ & $\begin{array}{r}-0.422 \\
0.405\end{array}$ & $\begin{array}{r}-0.057 \\
0.914\end{array}$ & $\begin{array}{r}-0.065 \\
0.903\end{array}$ & $\begin{array}{l}0.884 \\
\mathbf{0 . 0 2 0}\end{array}$ & $\begin{array}{l}1.000 \\
.\end{array}$ & & \\
\hline VEGF & $\begin{array}{l}\text { Spearman's rho } \\
\text { Sig. 2-tailed }\end{array}$ & $\begin{array}{l}0.096 \\
0.857\end{array}$ & $\begin{array}{r}-0.360 \\
0.483\end{array}$ & $\begin{array}{r}-0.367 \\
0.474\end{array}$ & $\begin{array}{r}-0.462 \\
0.356\end{array}$ & $\begin{array}{r}-0.214 \\
0.683\end{array}$ & $\begin{array}{r}-0.075 \\
0.887\end{array}$ & $\begin{array}{l}0.935 \\
\mathbf{0 . 0 0 6}\end{array}$ & $\begin{array}{l}0.809 \\
0.051\end{array}$ & $\begin{array}{c}1.000 \\
.\end{array}$ & \\
\hline TGF-b & $\begin{array}{l}\text { Spearman's rho } \\
\text { Sig. 2-tailed }\end{array}$ & $\begin{array}{r}-0.238 \\
0.650\end{array}$ & $\begin{array}{l}0.968 \\
\mathbf{0 . 0 0 2}\end{array}$ & $\begin{array}{l}0.982 \\
\mathbf{0 . 0 0 0}\end{array}$ & $\begin{array}{l}0.580 \\
0.227\end{array}$ & $\begin{array}{l}0.789 \\
0.062\end{array}$ & $\begin{array}{l}0.237 \\
0.652\end{array}$ & $\begin{array}{r}-0.504 \\
0.307\end{array}$ & $\begin{array}{r}-0.263 \\
0.614\end{array}$ & $\begin{array}{c}-0.392 \\
0.442\end{array}$ & 1.000 \\
\hline
\end{tabular}

Numbers in bold refer to statistically significant findings (correlations, 2-tailed). bFGF, basic fibroblast growth factor; IGF, insulin growth factor; PDGF, platelet derived growth factor; VEGF, vascular endothelial growth factor; TGF, transforming growth factor.

controls, an increased number of positive correlations was observed in the ID herniation group between most of the genes examined.

Correlation of transcript levels with clinicopathological characteristics

Age and gender. Age did not significantly affect the mRNA expression levels of the genes examined (minimum $\mathrm{P}=0.07$, Kruskal-Wallis test). Male patients exhibited increased mRNA expression levels of PDGF-C and -D compared with female patients $(\mathrm{P}=0.007$ and 0.024 , respectively, Mann-Whitney test) (absolute values not shown).

$B M I$. Significant negative correlations were observed between the patient BMI values and the transcript levels of VEGF, PDGFRA and PDGFRB $(\mathrm{P}=0.036,0.037$ and 0.02 , respectively, Spearman correlation).

Duration of symptoms. The transcript levels of PDGF-C and -D were significantly affected by the duration of patient symptoms $(\mathrm{P}=0.02$ and 0.05 , respectively, Kruskal-Wallis test). Specifically, patients suffering from acute pain ( $<3$ months) exhibited an increased mRNA expression of PDGF-C compared with those suffering for 3-10 months and for $>10$ months $(\mathrm{P}=0.04$ and 0.01 , respectively, Mann-Whitney test). Similarly, the PDGF-D expression levels were also significantly higher in patients suffering from acute ( $<3$ months) compared with chronic pain ( $\mathrm{P}=0.017$, Mann-Whitney test, Fig. 1).

Pain intensity. The intensity of patient pain significantly affected the expression levels of PDGF-B, -C and -D $(\mathrm{P}=0.044,0.024$ and 0.05 , Kruskal-Wallis test). Specifically, patients experiencing moderate pain (VAS 5-7) exhibited an increased mRNA expression of PDGF-B, -C and -D compared with those with low intensity pain (VAS 0-4) $(\mathrm{P}=0.01,0.018$ and 0.05 , respectively, Mann-Whitney test). In addition, patients with intense pain (VAS 8-10) also exhibited a significantly increased expression of PDGF-C and -D compared with those with low intensity pain $(\mathrm{P}=0.026$ and 0.03, respectively, Mann-Whitney test, Fig. 2).

Type of ID herniation. The transcript levels of VEGF significantly correlated with the type of ID herniation $(\mathrm{P}=0.023$, Kruskal-Wallis test). Specifically, ID herniation samples with protrusion exhibited an increased mRNA expression of VEGF compared with the extruded IDs $(\mathrm{P}=0.019$, Mann-Whitney test, Fig. 3).

Employment. The transcript levels of the genes examined did not differ significantly between patients with either light or heavy employment (minimum $\mathrm{P}=0.15$, Mann-Whitney test) (absolute values not shown).

Smoking. The mRNA expression levels of the GFs examined did not differ significantly between smoking and non-smoking patients (minimum $\mathrm{P}=0.087$, Mann-Whitney test). Accordingly, the amount of cigarette smoking did not significantly affect the transcript levels of any of the genes studied (minimum $\mathrm{P}=0.29$, Kruskal-Wallis test) (absolute values not shown).

\section{Discussion}

The current study examined the molecular profiles of numerous GFs by means of RT-qPCR in surgically resected 

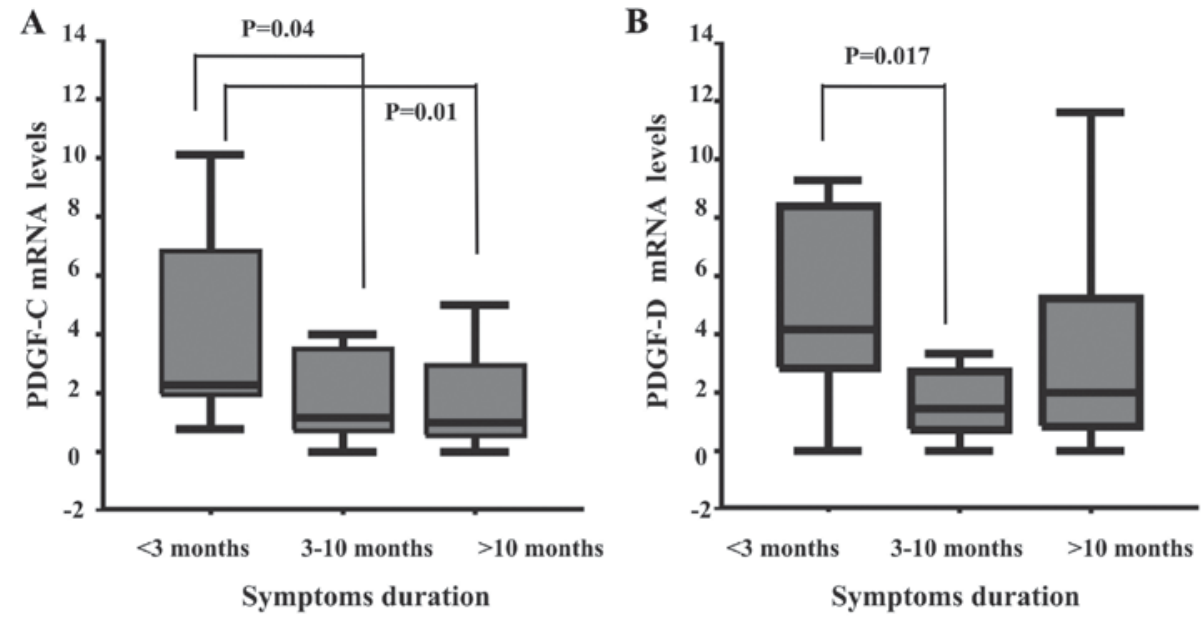

Figure 1. Normalized transcript levels of: (A) PDGF-C and (B) PDGF-D in regard to the duration of patient symptoms. PDGF, platelet derived growth factor.

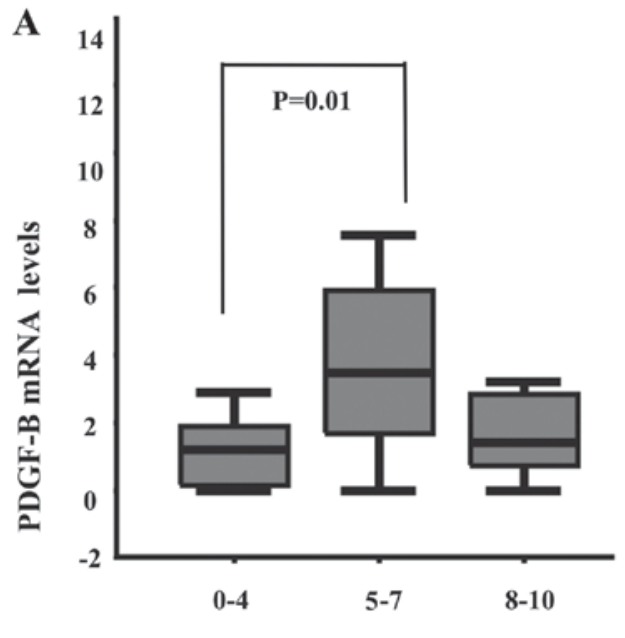

VAS

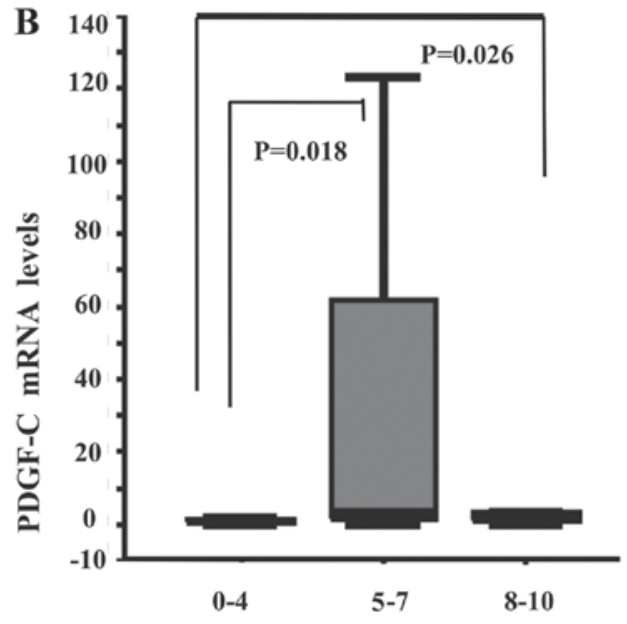

VAS

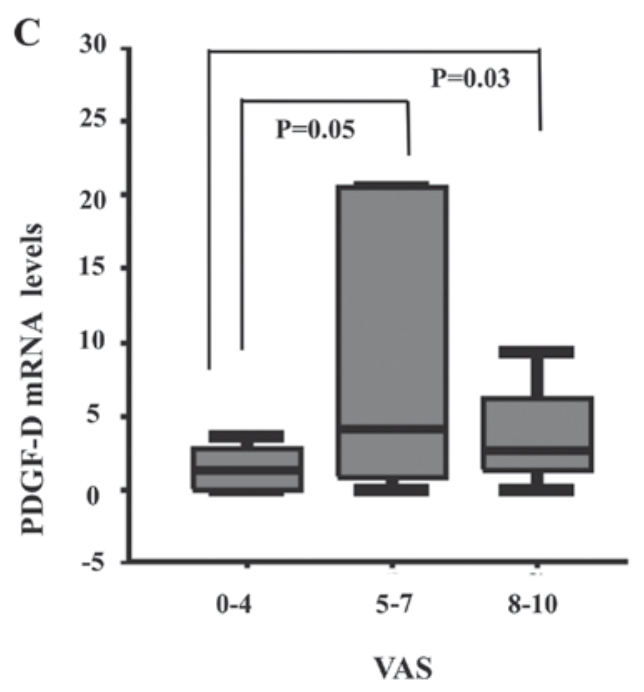

Figure 2. Normalized transcript levels of: (A) PDGF-B; (B) PDGF-C and (C) PDGF-D in regard to the intensity of pain experienced by the patients. PDGF, platelet derived growth factor; VAS, visual analogue scale.

lumbar ID herniation specimens and matched controls. Correlations of GF transcript levels with the patient clinical and epidemiological characteristics were also explored.
Multiple positive correlations between the GFs were identified in the group of herniated discs. The VEGF transcript levels were significantly higher in protruding compared with the 


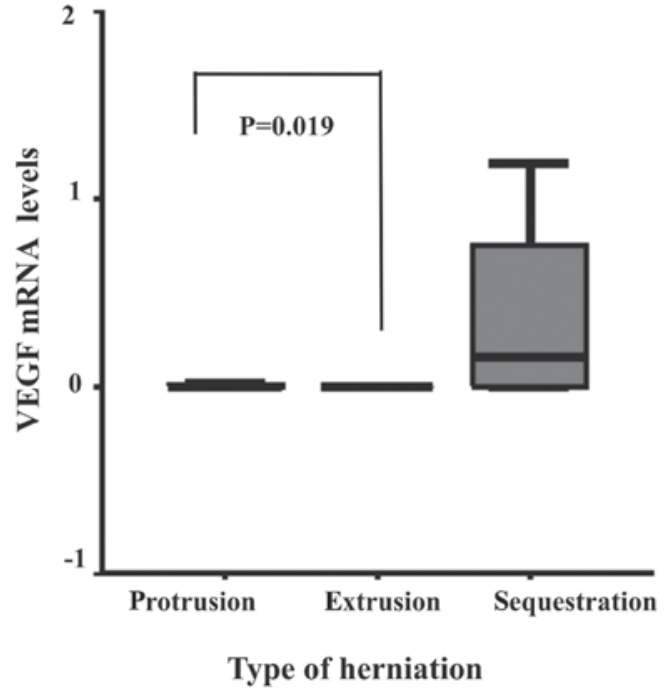

Figure 3. Normalized transcript levels of VEGF in regard to the type of ID herniation. ID herniation samples with protrusion exhibited an increased mRNA expression of VEGF compared with extruded discs ( $\mathrm{P}=0.019$, Mann-Whitney test). VEGF, vascular endothelial growth factor; ID, intervertebral disc.

extruded discs. The duration and intensity of patient symptoms significantly affected the PDGF transcript levels. BMI exhibited significant negative correlations with the transcript levels of VEGF and both PDGF-receptor isotypes (data not shown).

There have been limited reports in the literature examining the molecular profiles of GFs in ID herniation. In lumbar herniated IDs, Ahn et al detected TGF- $\beta$ mRNA expression in 5 out of 10 specimens examined (16), whereas Kontinnen et al found a decreased mRNA expression of the same factor (12). Control groups were not included in these studies. Kontinnen et al also failed to identify the mRNA or protein expression of EGF, which they attributed to the reduced anabolic potential of the disc. The findings of the present study did not identify any differences in the mRNA expression of GFs in a substantial number of herniated and control ID specimens. By contrast, immunohistochemistry, has produced more variable results. Specchia et al reported stronger staining for IGF-1 in chondrocytes of herniated compared with control discs (10). Similarly, Tolonen et al observed significantly stronger staining for PDGF and TGF- $\beta$ in human herniated ID tissue $(8,9)$. Given that no differences in GF expression are evident at the mRNA level compared with the controls, these findings suggest that post-transcriptional modifications may occur in the setting of ID herniation.

The transcript levels of the GFs examined significantly correlated with each other in herniated IDs. In vitro experiments have demonstrated a synergistic effect of VEGF and TGF- $\beta 1$ in the induction of angiogenesis (17). In addition, PDGF has been found to upregulate VEGF in mural cells, thereby further enhancing angiogenesis (18). IGF-I has also been shown to induce VEGF mRNA and protein expression in cultured colorectal carcinoma cells (19). Most of these GFs are also under the regulatory effect of inflammatory cytokines, such as interleukin-1 (IL-1) and tumor necrosis factor- $\alpha$ (TNF- $\alpha$ ). Both TNF- $\alpha$ and IL-1 have been shown to interact with numerous GFs in human degenerated discs and trigger a sequence of macrophage and MMP activation that potentiates the spontaneous resorption of herniated ID fragments (20-22). Multiple positive correlations between numerous MMPs have also been demonstrated in human ID herniation (5). Our findings, therefore, confirm a synergistic activation of GFs in ID herniation as part of a metabolic cascade that ultimately promotes the regression process of herniated discs.

Our results demonstrated that the transcript levels of VEGF were significantly higher in protruding compared with extruded IDs. VEGF is a potent mitogen for vascular endothelial cells. It induces new vessel formation through cell proliferation and luminal formation and has also been found to increase blood vessel permeability (23). Using immunohistochemistry, Tolonen et al and Koike et al confirmed the expression of VEGF in extruded and sequestrated human IDs $(9,24)$. A significant correlation was also observed between the expression of VEGF and the presence of vascular endothelial cells (24). Protruding ID herniation samples were not included in these studies. Ozaki et al reported the presence of small blood vessels in $73.4 \%$ of herniated ID tissues examined histopathologically, regardless of hernia type (25). They also suggested that neovascularization was present in the outermost annulus layers, even in protruding herniations. To the best of our knowledge, the present study is the first to confirm the expression of VEGF in protruding hernias at the mRNA level, thereby supporting the hypothesis that VEGF upregulation plays a key role even in the earliest stages of the neovascularization process that follows ID herniation.

PDGF is considered a key mediator in the tissue repair process. It stimulates mitogenicity and chemotaxis of neutrophils and macrophages in a variety of mesenchymal-derived cells, such as osteoblasts, chondrocytes and fibroblasts (7). It has been shown that PDGF exerts its effect on the repair process, not by altering its normal sequence, but by increasing its rate (26). It has been hypothesized that PDGF induces the production of extracellular matrix components and cellular proliferation in the ID in a similar mechanism as in the articular cartilage (9). It has also been shown to participate in the resorption process of herniated ID fragments by upregulating MMP expression (22). The findings of the present study indicated that the PDGF transcript levels were significantly higher in patients suffering from intense and acute pain. These findings support the role of PDGF as a key modulator of the repair process of damaged connective tissue, and indicate that it is primarily expressed in the acute phase of sciatica, during which it participates in a metabolic attempt to repair the herniated ID tissue.

Notably, PDGF isoforms -C and -D were the ones principally upregulated in patients with intense and acute pain. Among the PDGF isoforms, PDGF-BB is considered 'universal', mainly due to its ability to bind to both known forms of PDGF-receptor isotypes. In the musculoskeletal system, recombinant human PDGF-BB injection therapy has already been employed in experimental and clinical studies to promote fracture healing and foot and ankle fusion rates $(27,28)$. It is considered important in upregulating cytokines that enhance osseous and soft-tissue healing and regeneration. However, novel information on the biological actions of PDGF-C and -D isoforms has recently been added. PDGF-D was found to strongly attract macrophages to its expression sites and to inhibit the vascular leakage that results from growth factor-induced angiogenesis. When co-expressed with VEGF-E, it promotes the in vitro stability of the newly generated vessels induced by VEGF-E alone, leading 
to enlarged and less leaky vessels (29). Both neovascularization and subsequent macrophage infiltration are critical stages of the acute repair response following ID herniation. Our findings therefore suggest a more favorable effect of PDGF-CC and -DD isoforms in the acute phase of disc herniation and potentially provide an alternative target for growth factor therapy research. PDGF-CC isoform is known to bind to PDGF-R A/A and A/B dimers, whereas PDGF-DD binds to B/B dimers. B-receptor expression was found to be low in connective tissue cells and to increase during inflammation (30). In the present study, the expression of each receptor isotype was detected in approximately $50 \%$ of the herniated specimens. However, it was not significant compared with the controls.

BMI exhibited significant negative correlations with the transcript levels of VEGF and both PDGF-receptor isotypes. To the best of our knowledge, there is a paucity of data available on patient BMI in studies evaluating the molecular mechanisms implicated in ID herniation. As a consequence, BMI has not been previously associated with the expression of GFs in ID herniation. In a recent histo-morphological study, Weiler et al correlated histological disc alterations in surgical lumbar ID specimens with patient BMI, suggesting an accelerated course of ID degeneration in obese individuals (31). Occupational and lifestyle factors, including obesity, have been implicated in the pathogenesis of ID herniation, mainly on a biomechanical basis focusing on increased loading and structural failure of the disc $(32,33)$. However, a metabolic pathway may also exist. The findings of this study indicated that, in the obese population, a decrease in the expression of GFs directly associated with the acute repair process and regression of herniated IDs through peripheral neovascularization and chemotaxis. A previous study demonstrated the overexpression of TNF- $\alpha$ in the adipose tissue of obese individuals, as well as a consequent decrease with weight loss (34). In the ID, TNF- $\alpha$ has been shown to play a central signaling role in the metabolic cascade that regulates the natural history of degeneration and herniation by promoting the expression of other cytokines, MMPs and various GFs (16). Although a clear association cannot be established solely on the available evidence, these findings imply a molecular effet, in addition to the biomechanical effect of obesity in the pathogenesis and natural history of ID herniation.

In conclusion, the present study provides evidence of the simultaneous molecular profile of numerous GFs in herniated lumbar ID surgical specimens supporting the hypothesis of growth factor involvement in the natural history of ID herniation. GFs synergistically act in herniated IDs. Increased VEGF expression possibly induces the neovascularization process in the earliest stages of ID herniation. PDGF isoforms -C and -D potentially play a role in the acute phase of radiculopathy in a metabolic response for tissue healing. A molecular effect, in addition to the biomechanical effect of obesity in the pathogenesis and natural history of ID herniation is also suggested.

\section{References}

1. Taylor VM, Deyo RA, Cherkin DC and Kreuter W: Low back pain hospitalization. Recent United States trends and regional variations. Spine 19: 1207-1212, discussion 13, 1994.

2. Katz JN: Lumbar disc disorders and low-back pain: Socioeconomic factors and consequences. J Bone Joint Surg Am 88: 21-24, 2006.
3. Komori H, Shinomiya K, Nakai O, Yamaura I, Takeda S and Furuya K: The natural history of herniated nucleus pulposus with radiculopathy. Spine 21: 225-229, 1996.

4. Saal JA, Saal JS and Herzog RJ: The natural history of lumbar intervertebral disc extrusions treated nonoperatively. Spine 15: 683-686, 1990.

5. Tsarouhas A, Soufla G, Katonis P, Pasku D, Vakis A and Spandidos DA: Transcript levels of major MMPs and ADAMTS-4 in relation to the clinicopathological profile of patients with lumbar disc herniation. Eur Spine J 20: 781-790, 2010.

6. Masuda K, Oegema TR Jr and An HS: Growth factors and treatment of intervertebral disc degeneration. Spine 29: 2757-2769, 2004.

7. Alvarez RH, Kantarjian HM and Cortes JE: Biology of platelet-derived growth factor and its involvement in disease. Mayo Clin Proc 81: 1241-1257, 2006.

8. Tolonen J, Grönblad M, Virri J, Seitsalo S, Rytömaa T and Karaharju E: Transforming growth factor beta receptor induction in herniated intervertebral disc tissue: An immunohistochemical study. Eur Spine J 10: 172-176, 2001.

9. Tolonen J, Grönblad M, Virri J, Seitsalo S, Rytömaa T and Karaharju EO: Platelet-derived growth factor and vascular endothelial growth factor expression in disc herniation tissue: And immunohistochemical study. Eur Spine J 6: 63-69, 1997.

10. Specchia N, Pagnotta A, Toesca A and Greco F: Cytokines and growth factors in the protruded intervertebral disc of the lumbar spine. Eur Spine J 11: 145-151, 2002.

11. Tolonen J, Grönblad M, Virri J, Seitsalo S, Rytömaa T and Karaharju E: Basic fibroblast growth factor immunoreactivity in blood vessels and cells of disc herniations. Spine 20: 271-276, 1995.

12. Konttinen YT, Kemppinen P, Li TF, Waris E, Pihlajamäki H, Sorsa T, Takagi M, Santavirta S, Schultz GS and HumphreysBeher MG: Transforming and epidermal growth factors in degenerated intervertebral discs. J Bone Joint Surg Br 81: 1058-1063, 1999.

13. Thompson JP, Oegema TR Jr and Bradford DS: Stimulation of mature canine intervertebral disc by growth factors. Spine 16: 253-260, 1991.

14. Masuda K: Biological repair of the degenerated intervertebral disc by the injection of growth factors. Eur Spine J (Suppl 17) 4: 441-451, 2008.

15. Milette PC: Classification, diagnostic imaging, and imaging characterization of a lumbar herniated disk. Radiol Clin North Am 38: 1267-1292, 2000.

16. Ahn SH, Cho YW, Ahn MW, Jang SH, Sohn YK and Kim HS: mRNA expression of cytokines and chemokines in herniated lumbar intervertebral discs. Spine 27: 911-917, 2002.

17. Pepper MS, Ferrara N, Orci L and Montesano R: Potent synergism between vascular endothelial growth factor and basic fibroblast growth factor in the induction of angiogenesis in vitro. Biochem Biophys Res Commun 189: 824-831, 1992.

18. Guo P, Hu B, Gu W, Xu L, Wang D, Huang HJ, Cavenee WK and Cheng SY: Platelet-derived growth factor-B enhances glioma angiogenesis by stimulating vascular endothelial growth factor expression in tumor endothelia and by promoting pericyte recruitment. Am J Pathol 162: 1083-1093, 2003.

19. Warren RS, Yuan H, Matli MR, Ferrara N and Donner DB: Induction of vascular endothelial growth factor by insulin-like growth factor 1 in colorectal carcinoma. J Biol Chem 271: 29483-29488, 1996.

20. Kato T, Haro H, Komori H and Shinomiya K: Sequential dynamics of inflammatory cytokine, angiogenesis inducing factor and matrix degrading enzymes during spontaneous resorption of the herniated disc. J Orthop Res 22: 895-900, 2004.

21. Pratsinis H, Constantinou V, Pavlakis K, Sapkas G and Kletsas D: Exogenous and autocrine growth factors stimulate human intervertebral disc cell proliferation via the ERK and Akt pathways. J Orthop Res 30: 958-964, 2012.

22. Smith RJ, Justen JM, Sam LM, Rohloff NA, Ruppel PL, Brunden MN and Chin JE: Platelet-derived growth factor potentiates cellular responses of articular chondrocytes to interleukin-1. Arthritis Rheum 34: 697-706, 1991.

23. Ferrara N and Davis-Smyth T: The biology of vascular endothelial growth factor. Endocr Rev 18: 4-25, 1997.

24. Koike Y, Uzuki M, Kokubun S and Sawai T: Angiogenesis and inflammatory cell infiltration in lumbar disc herniation. Spine 28: 1928-1933, 2003.

25. Ozaki S, Muro T, Ito S and Mizushima M: Neovascularization of the outermost area of herniated lumbar intervertebral discs. J Orthop Sci 4: 286-292, 1999. 
26. Heldin $\mathrm{CH}$ and Westermark B: Mechanism of action and in vivo role of platelet-derived growth factor. Physiol Rev 79: 1283-1316, 1999.

27. Digiovanni CW, Baumhauer J, Lin SS, Berberian WS, Flemister AS, Enna MJ,Evangelista P and Newman J: Prospective, randomized, multi-center feasibility trial of rhPDGF-BB versus autologous bone graft in a foot and ankle fusion model. Foot Ankle Int 32: 344-354, 2011

28. Hee CK, Dines JS, Dines DM, Roden CM, Wisner-Lynch LA, Turner AS, McGilvray KC, Lyons AS, Puttlitz CM and Santoni BG: Augmentation of a rotator cuff suture repair using rhPDGF-BB and a type I bovine collagen matrix in an ovine model. Am J Sports Med 39: 1630-1639, 2011.

29. Uutela M, Wirzenius M, Paavonen K, Rajantie I, He Y, Karpanen T, Lohela M, Wiig H, Salven P, Pajusola K, et al: PDGF-D induces macrophage recruitment, increased interstitial pressure, and blood vessel maturation during angiogenesis. Blood 104: 3198-3204, 2004

30. Rubin K, Tingström A, Hansson GK, Larsson E, Rönnstrand L, Klareskog L, Claesson-Welsh L, Heldin CH, Fellström B and Terracio L: Induction of B-type receptors for platelet-derived growth factor in vascular inflammation: Possible implications for development of vascular proliferative lesions. Lancet 1 : 1353-1356, 1988.
31. Weiler C, Lopez-Ramos M, Mayer HM, Korge A, Siepe CJ, Wuertz K, Weiler V, Boos N and Nerlich AG: Histological analysis of surgical lumbar intervertebral disc tissue provides evidence for an association between disc degeneration and increased body mass index. BMC Res Notes 4: 497, 2011.

32. Pye SR, Reid DM, Adams JE, Silman AJ and O'Neill TW: Influence of weight, body mass index and lifestyle factors on radiographic features of lumbar disc degeneration. Ann Rheum Dis 66: 426-427, 2007.

33. Hangai M, Kaneoka K, Kuno S, Hinotsu S, Sakane M, Mamizuka N, Sakai S and Ochiai N: Factors associated with lumbar intervertebral disc degeneration in the elderly. Spine J 8: 732-740, 2008.

34. Kern PA, Saghizadeh M, Ong JM, Bosch RJ, Deem R and Simsolo RB: The expression of tumor necrosis factor in human adipose tissue. Regulation by obesity, weight loss, and relationship to lipoprotein lipase. J Clin Invest 95: 2111-2119, 1995. 